\begin{tabular}{|c|c|c|c|c|c|c|}
\hline \multirow{2}{*}{ LASER_WORDS } & IOPS & iops 1215 & $D$ & Dispatch: March 5, 2010 & Journal: IOPS & CE: Anand \\
\hline & Journ & Manuscript No. & & Author Received: & No of pages: 4 & TS: Lakshmi \\
\hline
\end{tabular}

Industrial and Organizational Psychology, 3 (2010), 1-4.

Copyright @ 2010 Society for Industrial and Organizational Psychology. 1754-9426/10

\title{
A Call to Context
}

PETER J. JORDAN

Griffith University

MARIE T. DASBOROUGH

University of Miami

CATHERINE S. DAUS

Southern Illinois University

NEAL M. ASHKANASY

The University of Queensland

In this reply to Cherniss (2010), we call for emotional intelligence (EI) scholars to direct more attention to the role of context. Before embarking on this endeavor, however, we first briefly respond to Cherniss's distinction between the ability model of $\mathrm{EI}$ and models based on emotional and social competencies (ESCs). We provide further evidence for the superiority of the ability model of $\mathrm{El}$, and discuss issues of predictive validity in relation to both models. Following this discussion, we address the importance of context, which is the main point of our commentary. Arguing that El may have differential effects depending on the situation in which the ability is being utilized, we proffer that this under-explored issue should be a priority for future El research.

Correspondence concerning this article should be addressed to Peter J. Jordan.

E-mail: Peter.Jordan@griffith.edu.au

Address: Griffith Business School, Griffith University, Nathan, Queensland 4111, Australia

Peter J. Jordan, Griffith Business School, Griffith University; Marie T. Dasborough, School of Business, University of Miami; Catherine S. Daus, School of Psychology, Southern Illinois University; Neal M.

Evidence for the Superiority of the Ability Model of EI

In the focal article, Cherniss differentiates between El (as epitomized in the ability model by Mayer and Salovey) and ESCs (as represented in mixed models, such as those by Bar-On and Goleman). We agree with Cherniss that the argument over which is the most pure definition of El has probably reached the point of overkill. We also agree with Cherniss that ESC models, while pragmatically useful, particularly in work-related contexts, are not El. As Ashkanasy and Daus (2005) point out, even the authors of the ESC models tend nowadays not to refer to them as El. From our perspective, this argument is moot, and we are perplexed as to why so many commentators appear to have missed this distinction.

As far as we can ascertain, the great majority of articles in the academic literature (and many of the popular press writings) consider Mayer and Salovey's (1997) definition and model as the "gold standard" for defining El. The points of disagreement seem to arise when we examine purported measures. In our opinion, measurement arguments clearly have plagued, 
dominated, and muddied the El definition discussion for too long.

A simple way to put this issue to rest is to look at what Mayer himself considers $\mathrm{El}$ to be. For example, in a recent Annual Review of Psychology article (Mayer, Roberts, \& Barsade, 2008), Mayer and his colleagues do not see ESC models to comprise even a portion of the El construct. Instead, they view these competencies as fitting within the personality domain. Their review of El highlights ability specific tests such as the Mayer-Salovey-Caruso emotional intelligence test (MSCEIT), the diagnostic analysis of nonverbal accuracy scale (DANVA), and the levels of emotional awareness scale (LEAS), all of which are solidly ensconced in the study of emotional abilities.

El, as Mayer and Salovey (1997) point out, requires a link between emotion and cognition. ESCs go beyond this, and we see them as a differentiated set of constructs incorporating aspects of personality. Later in his article, Cherniss notes that ESC models provide more predictive validity of work performance than El measures. Indeed, this conclusion is similar to the one reached by McClelland (1973) regarding the efficaciousness of measures of IQ when compared with competency measures. Thus, we agree with the essence of Cherniss's conclusions regarding the efficacy of the ESC models.

What Cherniss has not done, however, is to provide an explanation as to why measures of ESCs should provide greater predictive validity on job performance than El measures. We offer a simple explanation. As Jordan (2008) pointed out, ESC models are composite measures that include aspects of personality, attitudes, and personal preferences. On this basis, it seems reasonable to expect a broad measure to have more predictive ability than a narrow one (Ones \& Viswesvaran, 1996). Unfortunately, predictive ability does not directly translate to the percentage of variance explained by El. Although the overall predictive validity of El may be less than the ESC models, research has found that ability El exhibits greater incremental validity over personality variables than the ESC models (Côté \& Miners, 2006). Thus, ESC is best characterized not as a different form of $\mathrm{El}$, but rather as a personality construct. We argue that this explanation strengthens Cherniss's prescriptions for more clearly distinguishing the El and ESC approaches.

To investigate this point further, we looked at publications in a range of respected industrial-organizational (I-O) and management journals published in 2009. We wanted to ascertain what authors (and reviewers and editors), especially those who publish in the high profile journals in our literature, consider to be El. Following an examination of 2009 citations in Social Sciences Citation Index ${ }^{\circledR}$ regarding EI published at the time of writing this commentary, we found a strong preference for the ability model: The authors of 16 out of 21 articles approached El from an ability perspective. ${ }^{1}$ When we considered only top-tier journals ${ }^{2}$ published since 1999, the picture that emerges is even clearer: $A / l$ the empirical work and theoretical writing in these journals (10/10) was based on the ability model of El.

Thus, and as Ashkanasy and Daus (2005) point out, while the ESC models may work well in industry for diagnosis and development, the academics who publish in the higher profile outlets have steered away from this type of construct. Put simply, it is clear that researchers in respected journals are using the ability model of El as a framework for examining $\mathrm{El}$ in preference to ESC models.

1. Measurement tools vary widely, however, from the MSCEIT, to discrete ability tests such as the Situational test of emotional understanding (STEU: MacCann \& Roberts, 2008), to self-report measures based on the ability model, for example, the Schutte et al. (1998) SREIT and the Wong and Law (2002) WLEIS.

2. The journals we considered were those included in the Financial Times list: Academy of Management Journal; Academy of Management Review; Administrative Science Quarterly; Journal of Applied Psychology; Organizational Behavior and Human Decision Processes. 


\section{Importance of Context}

As we foreshadowed in our introduction, the main point we wish to make concerns the need to take more account of context in El research. Although Cherniss raises relevant issues about construct definitions, he appears to give the impression of adopting an altruistic perspective, as if El always has a positive effect. Our concern is that this may be interpreted by detractors of the $\mathrm{El}$ construct (e.g., Antonakis in Antonakis, Ashkanasy, \& Dasborough, 2009; Landy, 2005; Locke, 2005) as further evidence that $\mathrm{El}$ advocates naively regard $\mathrm{EI}$ as a Holy Grail. We credit Goleman (1995) for stimulating such perceptions by making overstated claims regarding the importance and effectiveness of El in his popular book, Emotional intelligence: Why it can matter more than IQ. Although a close reading of Cherniss's article reveals that he did indeed adopt a critical approach, we feel that it is necessary to clarify this point further, in particular by highlighting the role of context in El research.

As such, Ashkanasy and Dasborough (in Antonakis et al., 2009) put forward the idea that the positive effects of El may be principally associated with situations involving stress or social interactions. Moreover, there may even be a "dark side" to El in some situations. For example, in the particular context of leadership, Dasborough and Ashkanasy (2002) argue that leaders might use their El ability to carry out negative self-serving intentions in certain situations. There appear even to be some circumstances where low El may be useful. For example, Foo, Elfenbein, Tan, and Aik (2004) found that low El contributed to better outcomes in a negotiation task. Shiv, Loewenstein, Bechara, Damasio, and Damasio (2005) found in the context of investment decisions that investors suffering from neurological deficiencies in processing emotions made better decisions than investors without such deficits.

In this case, a legitimate research question is: When does low El lead to better performance outcomes? Perhaps even more intriguing is the possibility that within the same situation, some branches (or tasks) of El may be helpful and some may be harmful. For example, Cage and Daus (2006) found that customer service salespersons' ability to read faces was related to fewer items sold, and that the "understanding changes in emotional state" task of the MSCEIT was related to better sales performance.

A further compelling alternative is the possibility of a curvilinear relationship between El and performance, at least for some El branches and in some circumstances. For instance, although it is intuitive that too little emotional awareness might be debilitating when dealing with others, too much also may be problematic. For example, in the context of leadership, Antonakis (in Antonakis et al., 2009) raised the specter of "the curse of emotion" (p. 250), where a leader's over-attentiveness to maintaining agreeable emotions might be conducive to less effective leadership when a challenging situation calls for a hard-headed approach. Thus, emotionally intelligent leaders might be seen to have a tendency to avoid the challenging situations that lead to negative emotions for both leaders and followers (e.g., providing corrective feedback or taking necessary disciplinary action). Similarly, for the emotional management branch of El, Blagden and Craske (1996) found that excessive rumination led to greater experiences of negative affect. Thus, too much emotional awareness or too much emotional management might have the potential to be as debilitating as too little depending on the context and the task.

Accordingly, it appears that context should be a critical consideration in both El research and practice. Although we acknowledge that Cherniss does raise an interesting question about the role of context in relation to $\mathrm{El}$ at the very end of his commentary, our primary contribution is to give specific emphasis and examples from research regarding how context can influence the expression of $\mathrm{EI}$ and its concomitant outcomes. Our enthusiasm regarding examining context mirrors the most up to date thinking, research, and 
writing among both management scholars in general (e.g., Ashkanasy, 2007; Johns, 2006; Rousseau \& Fried, 2001), as well as EI and emotions researchers (Antonakis et al., 2008; Blagden \& Craske, 1996; Dasborough \& Ashkanasy, 2002; Foo et al., 2004; Shiv et al., 2005), and we are excited to see how this perspective influences future El thought and research.

\section{Conclusions}

We agree with Cherniss' differentiation of El and ESC models and posit that ESC models' greater predictive validity is likely because they tap a broader personality construct than El models. However, we believe that EI and ESC models differ in their contribution to incremental validity in the scientific study of emotions and emotional management. The academic community clearly prefers the ability model of $\mathrm{El}$ over the more populist ESC models. The important next step in the study of El is greater attention to the role of context in assessing the efficacy of $\mathrm{El}$ and its role in organizational settings. By explicating when high El (and what branches of it) would be helpful and harmful, the explanatory power of $\mathrm{El}$ is likely to continue to increase.

\section{References}

Antonakis, J., Ashkanasy, N. M., \& Dasborough, M. T. (2009). Does leadership need emotional intelligence? The Leadership Quarterly, 20, 247-261.

Ashkanasy, N. M. (2007). Revisiting JOB's mission Journal of Organizational Behavior, 28, 353-355.

Ashkanasy, N. M., \& Daus, C. S. (2005). Rumors of the death of emotional intelligence in organizational behavior are vastly exaggerated. Journal of Organizational Behavior, 26, 441-452.

Blagden, J. C., \& Craske, M. G. (1996). Effects of active and passive rumination and distraction: A pilot replication with anxious mood. Journal of Anxiety Disorders, 10, 243-252.

Cage, T., \& Daus, C. S. (2006, May). An Examination of Emotional Intelligence and Retail Performance. Presentation at the 21st Annual Meeting of the Society for Industrial/Organizational Psychologists. Dallas.

Cherniss, C. (2010). Emotional intelligence: Toward clarification of a concept. Industrial and Organizational Psychology, 3, xxx-xxx.

Côté, S., \& Miners, C. T. H. (2006). Emotional intelligence, cognitive intelligence, and job performance. Administrative Science Quarterly, 51, 1-28.
Dasborough, M. T., \& Ashkanasy, N. M. (2002). Emotion and attribution of intentionality in leadermember relationships. The Leadership Quarterly, 13, 615-634.

Foo, M., Elfenbein, H. A., Tan, H., \& Aik, V. (2004). Emotional intelligence and negotiation: The tension between creating and claiming value. International Journal of Conflict Management, 15, $411-429$.

Goleman, D. (1995). Emotional intelligence: Why it can matter more than IQ. New York: Bantam.

Johns, G. (2006). The essential impact of context on organizational behavior. Academy of Management Review, 31, 386-408.

Jordan, P. J. (2008). The use of emotional intelligence in business: Resolving varying definitions and measures and their relationship to work performance. In N. M. Ashkanasy \& C. L. Cooper (Eds.), Research companion to emotions in organizations (pp. 211-225). Cheltenham, UK: Edwin Elgar Publishing.

Jordan, P. J., Ashkanasy, N. M., \& Hartel, C. E. J. (2002). Emotional intelligence as a moderator of emotional and behavioral reactions to job insecurity. Academy of Management Review, 27, $1-12$.

Landy, F. J. (2005). Some historical and scientific issues related to research on emotional intelligence. Journal of Organizational Behavior, 26, 411-454.

Locke, E. A. (2005). Why emotional intelligence is an invalid concept. Journal of Organizational Behavior, 26, 425-431.

Mayer, J. D., Roberts, R. D., \& Barsade, S. G. (2008). Human abilities: Emotional intelligence. Annual Review of Psychology, 59, 507-536.

Mayer, J. D., \& Salovey, P. (1997). What is emotional intelligence? In P. Salovey \& D. J. Sluyter (Eds.), Emotional development and emotional intelligence: Educational implications (pp. 3-31). New York: Basic Books.

MacCann, C., \& Roberts, R. D. (2008). New paradigms for assessing emotional intelligence: Theory and data. Emotion, 8, 540-551.

McClelland, D. G. (1973). Testing for competence rather than for "intelligence". American Psychologist, 1, 1-14.

Ones, D. S., \& Viswesvaran, C. (1996). Bandwidthfidelity dilemma in personality measurement for personnel selection. Journal of Organizational Behavior, 17, 609-626.

Rousseau, D. M., \& Fried, Y. (2001). Location, location, location: Contextualizing organizational research. Journal of Organizational Behavior, 22, $1-13$.

Schutte, N. S., Malouff, J. M., Hall, L. E., Haggerty, D. J., Cooper, J. T., Golden, C. J., et al. (1998). Development and validation of a measure of emotional intelligence. Personality and Individual Differences, 25, 167-177.

Shiv, B., Loewenstein, G., Bechara, A., Damasio, H., \& Damasio, A. R. (2005). Investment behavior and the negative side of emotion. Psychological Science, 16, 435-439.

Wong, C. S., \& Law, K. S. (2002). The Effect of leader and follower emotional intelligence on performance and attitude: An exploratory study. Leadership Quarterly, 13, 243-274. 